\title{
La crítica del eurocentrismo y el pensamiento emergente en América Latina"
}

DAMí́N PACHÓN Soto* *

\section{Introducción}

En uno de los textos más famosos de la literatura latinoamericana, titulado "Nuestra América”, el escritor cubano José Martí dice: "Cree el aldeano vanidoso que el mundo entero es su aldea" (Martí, 1995, p. 121). Pues bien, lo que quiere decir Martí es que el aldeano, el habitante de esa aldea, de ese pueblo o de esa cultura es etnocéntrico, es decir, cree que su mundo es el centro del mundo. Pero, ¿qué es, entonces, el etnocentrismo? Es creer que todo lo nuestro es superior a lo que tienen los demás. En el etnocentrismo se cree que nuestro idioma, nuestras creencias y costumbres, nuestra religión, nuestra raza, nuestro sistema político, etc., son superiores que la lengua, la religión, las creencias, los sistemas políticos o la raza, de los demás, de las otras culturas. El etnocentrismo sobrevalora lo propio y subvalora lo otro. Está basado

* Este artículo es resultado de la investigación realizada en el marco del proyecto "Lecturas críticas del giro decolonial” del grupo Fray Bartolomé de las Casas. Se presentó como conferencia en la Universidad de Nanzan, Nagoya, Japón, el día 19 de mayo de 2016. Igualmente, en University of Foreing Studies, Kobe, Japón, el día 20 de mayo de 2016.

* Profesor Facultad de Filosofía y Letras. Doctor en Filosofía por la Universidad Santo Tomás. damianpachon@usantotomas.edu.co 
en la vanidad y en el orgullo propio. Desde este punto de vista, la cultura propia es el centro del universo, es la mayor creación existente.

El etnocentrismo consiste en creer que la propia cultura es superior y que las demás culturas son inferiores. La historia tiene muchos ejemplos: los griegos llamaban a los otros, a los no-griegos, bárbaros, es decir, casi animales o seres inferiores; los romanos creían que los demás eran bárbaros; los españoles en el siglo XVI creían que su cristianismo era la única religión verdadera; los alemanes en la época del nazismo creían que su raza, la raza aria, blanca, era superior a las otras razas del mundo. Esto quiere decir que el etnocentrismo ha sido común a través de la historia. Es una actitud común de los pueblos.

El objetivo de este artículo es tratar dos asuntos. El primero, el problema del eurocentrismo, entendido como la forma extrema de etnocentrismo en la modernidad (Santos, 2005); la segunda, mostrar la crítica que en América Latina se le ha hecho a la construcción histórica que ha legitimado ese eurocentrismo, poniendo de presente las posibilidades que esa crítica permite para el pensamiento emergente, nuevo, en Nuestra América. Me interesa mostrar cómo la crítica al eurocentrismo ha sido una tarea del pensamiento latinoamericano actual, lo cual ha sido necesario para pensar en otras filosofías, otras economías, otras formas de relacionarnos con la naturaleza. Es decir, es necesario criticar (deconstruir) la hegemonía cultural y el etnocentrismo europeo para crear otras formas de vivir, de convivir, de estar en el mundo.

Para realizar estos dos objetivos, voy a proceder de la siguiente manera: primero, voy a explicar cómo se formó el eurocentrismo y qué es exactamente; en segundo lugar, voy a mostrar la crítica que desde América Latina se le ha hecho al eurocentrismo desde la filosofía de la liberación, mostrando las posibilidades que la superación del eurocentrismo permite. 


\section{La formación del eurocentrismo y el establecimiento de su hegemonía}

Ya se dijo que el eurocentrismo es una clase particular del etnocentrismo. Ahora la pregunta que sigue es: ¿qué es, entonces, el eurocentrismo? El eurocentrismo es una construcción ideológica donde Europa aparece como una civilización superior a las demás. Es una Europa occidental y cristiana que considera que su civilización, su cultura, su filosofía, su liberalismo económico, su idea de progreso y de desarrollo, su ilustración, su modelo capitalista, en fin, su cosmovisión o visión del mundo, son un modelo que deben seguir los otros pueblos del planeta. El eurocentrismo es una idea según la cual Europa es el centro y América Latina, África y Asia son la periferia. Las culturas de la periferia deben repetir el modelo de civilización que Europa ha construido. Es la supremacía del mundo occidental sobre el resto.

¿Cuándo y cómo se formó esta idea de que Europa es el centro? ¿Quiénes construyeron esa ideología? La respuesta es sencilla. Esta ideología comienza en el periodo de la historia de Europa llamado el Renacimiento, el cual abarca más o menos desde el año 1300 al año 1600. En esta época, se divide la historia de Europa en tres partes: la Edad Antigua, la Edad Media, y la Edad Moderna. Así surge lo que el filósofo argentino-mexicano Enrique Dussel llama el paradigma eurocéntrico (Dussel, 2000). Es eurocéntrico precisamente porque toda la historia universal queda divida en tres partes según el modelo de Europa.

La Edad Antigua hace referencia a la historia de Grecia, luego de Roma y el Imperio romano. Esta termina en el siglo V después de Cristo con las invasiones bárbaras que destruyen el Imperio. Luego, comienza la Edad Media donde el cristianismo se extiende y se consolida. En este periodo se desarrolla una forma económica y social llamada feudalismo, dominada por la religión cristiana.

La Edad Media inicia su declive desde el siglo XI cuando los árabes invaden los lugares santos de Jerusalén en Israel y los cristianos comienzan las llamadas Cruzadas para tratar de recuperar esos lugares. En la lucha contra los árabes y la expansión europea por el Mar Mediterráneo se empieza a formar la clase comerciante que dará origen 
a la llamada burguesía. Esta burguesía creará, ya en el siglo XVI, el capitalismo. Por su parte, el Renacimiento es considerado una época de cambios, de transición entre la Edad Media y la Edad Moderna.

En esta lectura se considera que el mundo griego y romano fueron las culturas más avanzadas de la antigüedad. Después, cuando las invasiones bárbaras invaden al Imperio romano, inicia la Edad Media, la cual es vista como una época oscura, de atraso. Por eso a este periodo se le llama "el oscurantismo". En el Renacimiento lo que se busca es que Europa se vuelva a conectar con la Antigüedad, con la filosofía griega de Platón, Aristóteles; con el pensamiento de los romanos. De esta forma, los intelectuales del Renacimiento piensan que recuperando las ideas de Grecia y Roma es posible superar el oscurantismo de la Edad Media.

En esta división de la historia, la Edad Moderna se comienza a desarrollar en Europa. Se considera que la modernidad europea se debe a la Reforma de Martín Lutero, al nacimiento de la ciencia moderna en el siglo XVII con René Descartes, Galileo Galilei, Isaac Newton, etc. La modernidad se relaciona con el nacimiento del Estado moderno, especialmente, el Estado absolutista donde el rey tiene el poder absoluto. En este mismo periodo, especialmente a finales del siglo XVI, el capitalismo se empieza a consolidar en Inglaterra gracias al apoyo del Estado. La modernidad se consolida en el siglo XVIII con la llamada Ilustración.

Con esta Europa se ve a sí misma como una civilización madura, desarrollada, que ha progresado; es una Europa racional, capitalista, que se ve como producto de una evolución que inició con los griegos. A la vez, la periferia, lo que no es Europa, aparece como bárbaro, primitivo, no-civilizado (incivilizado), cuyas creencias, religiones, modos económicos, formas de organización política, Estado, Derecho, ciencia, pensamiento, etc., son atrasadas e irracionales (no-racionales).

Podemos decir, entonces, que el eurocentrismo se empieza a formar con el Renacimiento y se consolida en el siglo XVIII con la llamada Ilustración. Es en el siglo XVIII cuando Europa toma conciencia plenamente de su superioridad sobre otros pueblos, sobre otras culturas. La Ilustración es la autoconciencia de Europa (Gerbi, 1993). Sin embargo, esta autoproclamada superioridad de Europa sobre los otros pueblos solo puede entenderse teniendo en cuenta un conjunto de hechos que contribuyeron al dominio de Europa sobre el resto del mundo: 
me refiero a los descubrimientos geográficos y la expansión europea en África, Asia y América.

La expansión europea del siglo XV tiene como causa principal la toma de Constantinopla por los turcos en 1453. Con la toma de la ciudad, los europeos perdieron el contacto y las vías de acceso que los comunicaban con Asia, especialmente, con la India, la China, parte del Norte de África, y con lo que hoy es Medio Oriente. Por esa razón, los portugueses se vieron obligados a buscar una ruta diferente para llegar a la India y a la China. Fue en ese siglo cuando ellos iniciaron la exploración de las costas de África con el objetivo de llegar a Oriente.

En 1415 se toman la isla de Ceuta y en 1498 el navegante Vasco de Gama alcanza la India dándole la vuelta por el sur a todo el continente africano, "realizando, sin comparación, la travesía más larga hecha hasta entonces por un barco europeo remontándose en alta mar" (Parry, 2014, p. 49). Después, Cristóbal Colón buscando también llegar a Oriente, "descubre" América en 1492. De esta forma, al finalizar el siglo XV Portugal y España ya son dos potencias europeas que tienen colonias en la periferia de Europa. Al finalizar el siglo XVI Inglaterra arriba a Norte América y en el año 1600, los ingleses fundan la Compañía británica de las Indias Orientales.

Luego los holandeses se convertirán en la potencia marítima del siglo XVII, y llegarán a tener posesiones en Indonesia, Australia y América. También en el siglo XVI inicia el Imperio colonial francés con posesiones en Norteamérica, luego en Centro América y posteriormente en África.

Hay que agregar un dato importante. En 1521 Sebastián Elcano da la primera vuelta al mundo, en un viaje que había iniciado con el navegante Magallanes. Parten desde España, pasan por Sudamérica, llegan a las Filipinas, bordean el extremo sur de África y ascendiendo por sus costas regresan a España. Este viaje es significativo porque por primera vez el mundo es conocido de Norte a Sur y de Oriente a Occidente.

Con este conocimiento completo del globo se forma el llamado Sistema-mundo moderno, que luego se conectará económicamente y dará origen a una economía mundial capitalista (economía-mundo) de centro y periferias (Wallerstein, 2005). En el siglo XV, pues, el mundo dejar de tener tres partes (Asia, África y Europa), y pasa con América a tener cuatro. Y en el siglo XVI por primera vez el mundo es uno, está unido en 
su totalidad por las rutas de los exploradores y el poder de los Estados. Europa será el centro de ese sistema —mundo moderno/colonial—.

Todo esto quiere decir, que fue en el Renacimiento cuando Europa dominó los mares y comenzó su imperialismo sobre el resto de la tierra. Las tierras de la periferia pasaron a ser colonias de Europa. El centro dominaba la periferia. Ese dominio de los mares fue posible gracias a los adelantos técnicos como el astrolabio, que les permitió a los europeos mejorar la navegación, construir mejores barcos y navegar a mar abierto. Sin la brújula, la pólvora y también la riqueza acumulada, Europa no habría podido dominar el mundo.

El resultado de la expansión europea fue que el dominio militar sobre los otros pueblos acentuó la creencia en su superioridad natural. Es decir, que gracias a los imperios coloniales y al dominio militar sobre la periferia, Europa se vuelve hegemónica. Así nació el etnocentrismo europeo o, para decirlo sencillamente, así nació el eurocentrismo. Por eso, ya en el siglo XVIII la superioridad de Europa no se discutía, se daba por hecho, se asumía como algo obvio. Esto fue legitimado por el filósofo alemán Friedrich Hegel quien pensaba que la historia seguía la ruta del sol: "La historia universal va de Oriente a Occidente. Europa es absolutamente el término de la historia universal. Asia es el principio" (1974, p. 201).

Para Hegel, la historia inicia en Asia, pasa por Grecia y termina en Francia, Inglaterra, Dinamarca y Alemania que son vistas como el "corazón” de Europa. Todo lo demás, era inferior y había quedado superado. De esta manera Hegel les da el "derecho absoluto" a los pueblos del Norte sobre los demás pueblos del mundo, esto es, Hegel legitima el colonialismo desde su filosofía (Dussel, 1994).

Hegel, junto con los románticos alemanes de la época, entre ellos, J. W. Goethe, ve el comienzo de la cultura y de la filosofía en Grecia. El desarrollo del pensamiento pasa por Descartes, Kant y llega hasta el propio Hegel, también conocido como el Aristóteles de Berlín. Sin embargo, lo que hace Hegel es una construcción intelectual donde el desarrollo de la cultura desemboca en su propio tiempo. Hegel solo formuló filosóficamente el eurocentrismo. Pero, de hecho, ya en la España del siglo XVI se decía que los habitantes de América eran bárbaros, incultos, caníbales, y en fin, tan inferiores a los europeos como 
lo eran los niños a los adultos, las mujeres a los varones y los monos a los hombres (Sepúlveda, 1996, p. 101).

Por su parte, Francis Bacon, el creador del método inductivo moderno, y uno de los padres de la ciencia, sostuvo en 1620: "se pueden señalar tres revoluciones o épocas de la ciencia: una con los griegos, la segunda con los romanos y la última con nosotros, es decir, con las naciones de Europa occidental a cada una de las cuales podemos atribuir dos siglos" (N.O., I, 78; Works., VIII, p. 110). Para Bacon también, incluso 200 años antes que Hegel, Europa es la cima de la civilización, es una época más desarrollada científicamente.

En Francia, el Barón de Montesquieu el creador de la moderna teoría de la división de poderes (ejecutivo, legislativo y judicial), es un claro ejemplo del etnocentrismo racista europeo. Al respecto decía:

Si yo tuviera que defender el derecho que hemos tenido los blancos para hacer esclavos a los negros, he aquí todo lo que diría [...] la prueba de que los negros no tienen sentido común, es que prefieren un collar de vidrio a uno de oro, cuando el oro es tan estimable en los países cultos (2000, p. 162).

Lo que sostiene Montesquieu en este libro clásico, es que la esclavitud de la raza negra es legítima, pues los negros no tienen sentido común. Descartes había dicho que "el buen sentido [la razón. D.P.] es la cosa que mejor repartida está en el mundo [...] es por naturaleza igual en todos los hombres (1986, p. 69), sin embargo, para Montesquieu esto no es estrictamente cierto. El pensador ilustrado francés sostiene no solo la superioridad de la raza blanca [racismo, D.P.], sino también de las valoraciones y estimaciones de esa cultura. Podríamos preguntarnos: ¿por qué los negros tienen que valorar el oro de la misma manera que los blancos? En este mismo sentido racista dirá el filósofo alemán Inmanuel Kant que "algunas razas americanas representan el escalón más bajo de la humanidad” (Gerbi, 1993, p. 418). Razas que son infantiles, inmaduras, menores de edad, no ilustradas.

Podemos preguntarnos ahora: ¿qué implicaciones tiene el eurocentrismo? Resumiendo podríamos señalar las siguientes 10 consecuencias: 
1. Tiene como fuente el dominio militar, el colonialismo político y económico sobre los pueblos conquistados,

2. es decir, el eurocentrismo es posible gracias a la violencia propia de toda relación colonial, pues no hay modernidad sin colonialismo, son dos caras de la misma moneda (Mignolo, 2007, p. 18).

3. En este proceso, la "civilización moderna se comprende como más desarrollada, superior” (Dussel, 2005, p. 49). Por eso aparece como "universal", válida para todos.

4. De esa superioridad surge el deber moral, ético, de civilizar y desarrollar a los pueblos atrasados.

5. En ese proceso de modernización surgen víctimas. Son las víctimas de la modernidad, del progreso, del desarrollo económico. Esas víctimas son vistas como producto necesario de la civilización (Dussel, 2005).

6. Se justifica la necesidad de que el sistema capitalista, las ideas liberales, la democracia liberal, la idea de desarrollo, etc., se extiendan por todas las partes del globo alcanzando a todas las otras culturas.

7. Se inferiorizan, desprecian y se destruyen todas las otras culturas, religiones, creencias, epistemologías, economías o formas de intercambio con la naturaleza. Para enfatizar y poner de presente esa inferioridad se usan expresiones como "Tercer mundo", “culturas subdesarrolladas”, etc., (Santos, 2005, p. 347).

8. Se invisibiliza al otro, no se lo reconoce, se desechan y se desperdician otras experiencias y otras formas de ver, sentir y pensar.

9. Todo lo anterior, legitima la colonialidad del saber o, más precisamente, el "colonialismo intelectual" sobre los países y las culturas del "Tercer mundo".

10. Con la formación del mundo moderno colonial, y eurocéntrico, se acelera la historia, se genera una forma-vida-frenesí, rápida, esquizofrénica, veloz (Pachón, 2013).

Este “decálogo" de consecuencias negativas del eurocentrismo, también es aplicable a los Estados Unidos pues después de la Segunda 
Guerra Mundial este país adquiere un gran poderío militar, económico y cultural. Se pone de moda "The american way of life". Con los Estados Unidos tenemos entonces un Norte hegemónico compartido con Europa. Es lo que se puede llamar un nuevo "nordocentrismo". Estados Unidos hereda, de cierta forma, la hegemonía europea.

\section{El pensamiento emergente y la crítica del eurocentrismo}

La crítica del eurocentrismo en América ha tenido dos grandes momentos. Uno en el siglo XIX y el otro a partir de 1960. En el siglo XIX, de hecho, Simón Bolívar, el libertador de Colombia, Venezuela, Ecuador, Perú y Bolivia, entendió al final de su vida que América no debía copiarse todo de Europa. Decía en 1828, cuando Suramérica ya se había independizado de España, que:

Yo creo que el nuevo gobierno que se dé a la república debe estar fundado sobre nuestras costumbres, sobre nuestra religión, sobre nuestras inclinaciones, y últimamente, sobre nuestro origen y nuestra historia. La legislación de Colombia no ha tenido efecto saludable, porque ha consultado libros extranjeros, enteramente ajenos de nuestras cosas y nuestros hechos (Bolívar, S.f., IV, p. 1183).

Lo que Bolívar dice es que no debemos copiarnos de Europa, así ella pertenezca a nuestro pasado, a nuestra historia. Para Bolívar, es más importante darnos un gobierno, un Estado, un Derecho, con base en nuestra propia realidad, nuestra religión y nuestras costumbres. Por su parte, José Martí, el pensador cubano que murió buscando la libertad de Cuba, en 1895, afirmaba que las instituciones y el gobierno debían nacer de los elementos naturales de cada país, de la propia realidad. Decía: “[...] y el buen gobernante en América no es el que sabe cómo se gobierna el alemán o el francés, sino el que sabe con qué elementos está hecho su país" (1995, p. 122). La idea es la misma de Bolívar: el gobierno y las instituciones han de nacer del país y no de Estados Unidos, 
Francia o Inglaterra. Sin embargo, esta naciente crítica al eurocentrismo y al nordocentrismo estaba guiada, ante todo, por el deseo de una independencia política, ya que el fin y el deber de los latinoamericanos después de la independencia eran la autonomía y el autogobierno.

La crítica más fuerte al eurocentrismo surge en la segunda mitad del siglo XX, más o menos a partir de 1960. Esta crítica aparece con las nuevas corrientes de pensamiento y con el nacimiento de las ciencias sociales críticas: sociólogos, historiadores, economistas, y filósofos se enfrentaron a la visión hegemónica de Europa. Entre las corrientes de esa época podemos mencionar la crítica de la teoría de la dependencia [Cardozo y Faletto, (1969)], la sociología de Orlando Fals Borda (1971), la teología de la liberación (Scannone, II, 2005) y la filosofía de la liberación Dussel (2014), entre otras.

A continuación, me referiré a la crítica que se le ha venido haciendo al eurocentrismo y su narrativa histórica. Este es un punto de partida fundamental, como mostraré más adelante, para las nuevas corrientes de pensamiento emergente en la región, en especial, para fundamentar sus demandas. Esta crítica al eurocentrismo está desarrollada básicamente por el filósofo argentino y mexicano Enrique Dussel.

Lo que ha hecho Enrique Dussel desde América Latina es construir una nueva visión de la historia, una historia mundial (en oposición a la historia universal de Hegel) reformulando la narrativa histórica que ha permitido legitimar el eurocentrismo (Dussel, 2007). Se trata de mostrar que la línea histórica Grecia-Roma-Edad Media-Renacimiento y Edad Moderna no es correcta; es ideológica y además deja la historia y los aportes de muchos pueblos por fuera. Es decir, que esa línea histórica desconoce y margina las contribuciones de otras culturas. Se trata de cambiar la historia eurocéntrica por una historia mundial que incluya la historia, las contribuciones y aportes de otras culturas.

Por eso, la primera tarea que se debe hacer es deconstruir el helenocentrismo, es decir, la idea de la centralidad de Grecia en el mundo antiguo. De hecho, para Dussel, el helenocentrismo es el padre del eurocentrismo. Se trata de mostrar por ejemplo, que:

La filosofía [...] no nació en Grecia continental, sino en Egipto y las ciudades fenicias, y por ello entre los griegos esta actividad se 
inició en la Hélade marítima, de ciudades portuarias, comerciales, en antigua convivencia con las costas del delta del Nilo y de las ciudades del Este del Mediterráneo (2007, p. 58).

Cabe destacar que Atenas fue colonia de una ciudad Egipcia llamada Saís tal como aparece en el Timeo de Platón; Aristóteles reconoce en la Metafísica que los primeros sabios que se dedicaron a pensar fueron los egipcios; tanto Pitágoras como Demócrito aprendieron gran parte de sus teorías en Egipto. Asimismo, la palabra demos, que forma la palabra democracia o poder del pueblo, significa en egipcio "aldea"; también la palabra díke que significa justicia proviene del acadio $d u k u$, es decir, es semita. Por lo demás, solo Platón y Aristóteles nacieron en lo que actualmente es Grecia, mientras que los otros filósofos eran de la actual Italia o de islas en el Mediterráneo como Abdera, Efeso, etc. En cuanto a los romanos ellos dejaron un legado importante en el Derecho, pero en filosofía no alcanzaron el genio de los griegos. "a diferencia de los griegos, los romanos no eran pensadores especulativos y metafísicos, sino, principalmente, hombres prácticos" (Copleston, 2001, p. 380).

Asimismo, la Edad Media europea es una etapa que solo vivió Europa, no el resto del mundo. Es una Edad Media latina, cristiana y feudal. Ese feudalismo es típicamente europeo. Además, entre el siglo V y el siglo XIII no hay todavía idea de Europa, no hay idea de una Europa occidental, y tampoco Europa es el centro. De hecho, en estos siglos la Europa latina que surgió con la destrucción del Imperio romano está encerrada, ensimismada, rodeada por el Imperio bizantino más griego y oriental y en el Sur rodeada por el Islam, por los árabes.

Por otro lado, la línea Grecia-Roma-Renacimiento es reductiva y deja por fuera los aportes del mundo árabe, el cual fue hegemónico por casi 1000 años, desde el siglo VII cuando nace Mahoma hasta cuando son expulsados de Europa en el siglo XVI. Lo que pretendieron los pensadores del Renacimiento, llamados humanistas, fue recuperar la cultura antigua griega y romana. Sin embargo, la filosofía griega, por ejemplo, fue estudiada, cultivada y comentada en el mundo árabe, en Alejandría y en Bagdad. Fueron los árabes quienes hicieron comentarios y estudios sobre Platón y Aristóteles. Primero se leyó a Aristóteles en 
Bagdad, en Irak, que en París. Fueron los españoles, desde el siglo XII, los que fundaron la "Escuela de Traductores de Toledo, donde tradujeron al latín los estudios que los árabes habían hecho sobre los griegos. De tal manera que el renacer filosófico de Europa solo es posible con el aporte de los árabes. Además, "en astronomía, física, medicina, óptica, alquimia, matemáticas e ingeniería [...] (la casa del Islam) estaba muy por encima del occidente latino" (Principe, 2013, pp. 18-19).

Para Dussel Europa solo se constituyó como centro a partir de 1492, cuando surge verdaderamente una modernidad mundial que luego Descartes formalizará con el ego cogito, que tiene como antecedente el ego conquiro (el yo conquisto). Con 1492 Europa saca una ventaja comparativa que le permitirá ser hegemónica en los siglos siguientes, en la segunda modernidad, que ya recoge los frutos de la periferialización posible solo después del "Descubrimiento". Hegel desconoció todo esto. Para Dussel, además, la historia no avanza de Oriente a Occidente como pensaba Hegel, donde América Latina sería un producto de la Europa Occidental. Por el contrario, América es el "extremo oriental de Oriente" (2014, p. 24), pues finalmente fueron los orientales los que arribaron al continente americano, hace más de 20 mil años por el estrecho de Bering.

Por último, hay que decir que lo que conocemos como sistema capitalista no existiría sin los aportes de América. Fueron las riquezas de América, el oro y la plata, las que le permitieron a Inglaterra acumular capital. Esto aparece claramente en los estudios de Karl Marx (1995) cuando sostiene:

El descubrimiento de los yacimientos de oro y plata en América, la cruzada de exterminio, esclavización y sepultamiento en las minas de la población aborigen, el comienzo de la conquista y el saqueo de las Indias Orientales, la conversión del continente africano en cazadero de esclavos negros: son todos hechos que señalan los albores de la era de producción capitalista. Estos procesos idílicos representan otros tantos factores fundamentales en el movimiento de la acumulación originaria (p. 638). 
Sin América Latina y sus riquezas no hubieran existido ni capitalismo, ni modernidad. Europa y la modernidad europea no se crearon a sí mismas sin contacto con el mundo periférico; la modernidad no es un producto endógeno, intra-europeo, por el contrario, se alimentó de otras culturas. Como dice Leopoldo Zea: "Todos los pueblos alimentan y posibilitan una Europa que va poco a poco, desarrollándose, desechando como cáscaras vacías a los pueblos de los que se ha servido" (1990, p. 203). Hay que tener en cuenta, además, que el contacto con Oriente y con otros pueblos de la llamada periferia le sirvió a Europa para definir su identidad. Pues toda identidad se crea oponiendo un nosotros y un ellos. Edward Said (2002) en su libro Orientalismo dice:

El desarrollo y el mantenimiento de cualquier cultura requiere la existencia de otro alter ego diferente y competitivo. La creación de una identidad [...] implica establecer antagonistas y 'otros' cuya realidad esté siempre sujeta a una interpretación y a una reinterpretación permanentes de sus diferencias con nosotros (p. 436).

\section{Conclusiones}

En la primera parte se mostró qué era el eurocentrismo y cómo se formó en Europa; en la segunda se hizo una crítica a la narrativa histórica que justifica habitualmente ese eurocentrismo. Se mostró que era necesario criticar la línea Grecia-Roma-Edad Media-Edad Moderna, porque ocultaba los aportes a la historia mundial de otros pueblos como los egipcios, los árabes y los americanos. Ahora lo que interesa mostrar aquí es por qué esta crítica es importante para el pensamiento nuevo en América Latina, y no solo en nuestro continente, sino en otros lugares. Veamos algunas razones:

1. Se sitúa la historia de Europa como una historia más, como una historia particular, que no se puede hacer valer para el resto del orbe. Es decir, nos permite entender que la historia de Europa no es universalizable, ni aplicable a otros pueblos. Se trata de 
“provincializar a Europa” de-construyendo sus pretensiones hegemónicas (Chakrabarty, 1999, p. 653).

2. Permite hacer visibles otras historias de otros pueblos, otras naciones, y nos posibilita valorar sus culturas.

3. Nos permite cuestionar categorías como progreso, desarrollo y experimentar otras formas de concebir lo humano, el bienestar y el buen vivir. Esto implica criticar la economía vigente, y su lógica de acumulación, así como sus valores eficientistas, exitistas e individualistas. Permite rescatar otras economías y otra manera de gestionar los bienes. La crítica de la historia hegemónica lleva a que rescatemos otras filosofías, otras teorías políticas, otras tradiciones de pensamiento que nos pueden aportar para enfrentar los problemas y los desafíos que tenemos en las sociedades actuales.

4. Hace posible cuestionar y replantear el trato del hombre con la naturaleza, y pensar en una relación más armónica con el entorno y el cosmos.

5. Implica comprender que hay otras maneras de producir conocimiento, que hay otras epistemologías. Esto es importante porque el colonialismo siempre ha eliminado otros saberes; el colonialismo ha estado basado en el "epistemicidio" (Sousa Santos, 2009, p. 12), imponiendo así sus propias formas de conocer y ocultando las del dominado.

6. Fomenta y promueve el dialogo intercultural (Fornet-Betancur, 2008) e inter-filosófico, por ejemplo, entre las filosofías aborígenes, hindúes, chinas, japonesas, africanas y europeas.

7. Nos permite hacer justicia cognitiva, recuperar otras memorias, y así agrandar y expandir el saber universal.

8. Nos posibilita abrir el pensamiento, superar el colonialismo mental e intelectual favoreciendo la creatividad humana.

9. En fin, permite ampliar y valorar las experiencias y las prácticas de la humanidad toda, en su conjunto.

10. No se trata de desconectarse del mundo, ni de rechazar algunos de los valores que Europa nos ha legado; ni tampoco se trata 
de rechazar la ciencia, la técnica, los adelantos tecnológicos, ni los avances médicos. Esto sería irracional y estúpido. Se trata de enderezar el camino, de cambiar y corregir todo aquello que está dañando la vida en sus múltiples formas, para lo cual se necesita también una transformación de las relaciones de fuerza en las que están inscritas las relaciones identitarias dominadas y dominantes (Castro-Gómez, 2015).

La filósofa española María Zambrano decía “nada real debe ser humillado" (1990, p. 69). Esta frase sencilla quiere decir que debemos acoger lo que existe y lo que nos rodea. Tal vez así aprendamos nuevas formas de vivir y nuevas formas de morir. Esta es la actitud que tienen algunas de las filosofías en Latinoamérica actualmente, como las filosofías de la vida, la filosofía intercultural y nuevas filosofías de la economía. Por eso la crítica al eurocentrismo y al nordocentrismo ha sido fundamental, pues permite cuestionar el mundo que tenemos y nos invita a crear y levantar el vuelo hacia otras direcciones.

\section{Referencias}

Bacon, F. (2011). La Gran Restauración. [Traducido al <español> de <Novum Organum>]. Madrid, España: Tecnos.

Bacon, F. The Works of Francis Bacon. (1857-1874). Recuperado de, http:// onlinebooks.library.upenn.edu/webbin/metabook?id=worksfbacon

Bolívar, S. (s.f.). Obras completas, Vol., IV. Cali, Colombia: Fundación para la Investigación y la cultura.

Cardozo, F. y Faletto, E. (1969). Dependencia y desarrollo en América Latina. México D.F., México: Siglo XXI Editores.

Castro-Gómez, S. (2015). Revoluciones sin sujeto. Slavoj Zizeck y la crítica del historicismo posmoderno. México D.F., México: Akal.

Chakrabarty, D. (1999). "La poscolonialidad y el artilugio de la historia: ¿quién habla en nombre de los pasados indios?”. En S. Dube (Comp.), Pasados poscoloniales, (pp. 623-658). México D.F., México: El Colegio de México.

Copleston, F. (2001). Historia de la filosofía. Tomo I: Grecia y Roma. Barcelona, España: Ariel. 
Descartes, R. (1986). Discurso del método. Madrid, España: Alianza Editorial. Dussel, E. (1994). 1492: El encubrimiento del otro. El origen del mito de la modernidad. La Paz, Bolivia: Plural.

Dussel, E. (2005). Europa, modernidad y eurocentrismo. En E. Lander, (Comp.). La colonialidad del saber: eurocentrismo y ciencias sociales. Perspectivas Latinoamericanas (pp. 41-53). Buenos Aires, Argentina: Clacso.

Dussel, E. (2007). Política de la liberación. Historia mundial y crítica. Madrid, España: Editorial Trotta.

Dussel, E. (2014). Filosofía de la liberación. México D.F., México: Fondo de Cultura Económica.

Dussel, E. (2000). Ética de la liberación en la edad de la globalización y la exclusión, 3a ed., Madrid: Trotta.

Fals Borda, O. (1971). Ciencia propia y colonialismo intelectual. Bogotá, Colombia: Oveja Negra.

Fornet-Betancur, R. (Julio de 2008). Teoría y praxis de la filosofía intercultural. Trabajo presentado en el XII Congreso Internacional de Filosofía Latinoamericana de la Universidad Santo Tomás, Bogotá, Colombia.

Gerbi, A. (1993). La disputa del Nuevo Mundo. Historia de una polémica 1750-1900. México D.F., México: Fondo de Cultura Económica.

Hegel, G. W. F. (1974). Lecciones sobre la filosofía de la historia universal. Madrid, España: Revista de Occidente.

Martí, J. (1995). Nuestra América. En: L. Zea (Comp.), Fuentes de la cultura latinoamericana Vol., I. (pp. 121-127). México D.F., México: Fondo de Cultura Económica.

Marx, K. (1975). El capital. Volumen 1, México D.F., México: Fondo de Cultura Económica.

Mignolo, W. (2007). La idea de América. La herida colonial y la opción decolonial. Barcelona, España: Gedisa.

Monstesquieu, C. (2000). Del espíritu de las leyes, México D.F., México: Porrúa.

Pachón, D. (2013). Preludios filosóficos a otro mundo posible. Bogotá, Colombia: Ediciones Desde abajo.

Parry, J. (2014). Europa y la expansión del mundo 1415-1715, México D.F., México: Fondo de Cultura Económica. 
Principe, L. (2013). La revolución científica. Una breve introducción. Madrid, España: Alianza Editorial.

Said, E. (2002). Orientalismo, Barcelona, España: Random House Mondadori.

Santos, J. (2005). Etno-eurocentrismo. En R. Salas (Comp.), Pensamiento crítico latinoamericano, Vol., I, (pp. 341-354). Santiago de Chile, Chile: Ediciones Universidad Católica Silva Henríquez.

Scannone, J. (2005). "Filosofía/Teología de la liberación”. En R. Salas (Comp.), Pensamiento crítico latinoamericano, Vol., II, (pp. 429-442). Santiago de Chile, Chile: Ediciones Universidad Católica Silva Henríquez.

Sepúlveda, J. (1996). Tratado de las justas causas de la guerra contra los indios. México D.F., México: Fondo de Cultura Económica.

Sousa Santos, B. (2009). Una epistemología del sur. México D.F., México: Siglo XXI editores y Clacso.

Wallerstein, I. (2005). Análisis del sistema-mundo. Una introducción. México D.F., México: Siglo XXI editores.

Zambrano, M. (1990). Claros del bosque, Barcelona, España: Seix Barral.

Zea, L. (1990). Discurso desde la marginación y la barbarie. México D.F., México: Fondo de Cultura Económica. 
